\title{
EGFRvIII mutation in lung cancer correlates with increased EGFR copy number
}

\author{
HIDEFUMI SASAKI, OSAMU KAWANO, KATSUHIKO ENDO, \\ HARUHIRO YUKIUE, MOTOKI YANO and YOSHITAKA FUJII \\ Department of Surgery II, Nagoya City University Medical School, \\ 1 Kawasumi, Mizuho-cho, Mizuho-ku, Nagoya 467-8601, Japan
}

Received August 21, 2006; Accepted October 31, 2006

\begin{abstract}
Overexpression of the epidermal growth factor receptor $(E G F R)$ is caused by $E G F R$ gene amplification and is sometimes associated with expression of a variant $E G F R$ (deletion exon 2-7 or EGFRvIII). EGFRvIII mutation has oncogenic potential and is investigated as a potential therapeutic target. We genotyped the EGFRvIII mutation status in 252 surgically treated lung cancer cases. The presence or absence of EGFRvIII mutation was analyzed by real-time quantitative polymerase chain reaction (PCR) with mutation specific sensor and anchor probes. EGFR copy number was evaluated with PCR-based assay. EGFR mutation status at kinase domain has been examined and reported. EGFRvIII mutation was found on 8 of 252 patients. All patients were male, smokers, and 7 had squamous cell carcinoma. The mutation status was significantly correlated with pathological subtypes (squamous cell carcinoma vs. adenocarcinoma, $\mathrm{p}=0.0114)$. Sixty $E G F R$ mutations at kinase domain exclusively existed with EGFRvIII mutations. EGFR gene copy number was significantly higher in EGFRvIII mutant $(4.711 \pm 4.968)$ than in non-EGFRvIII mutant $(2.284 \pm 1.224)$ $(\mathrm{p}=0.0001)$. EGFRvIII gene mutation might be one of the mechanisms of increased EGFR copy number. Further studies are needed to confirm the mechanisms of EGFRvIII mutations for possible anti-EGFR therapy for lung cancer.
\end{abstract}

\section{Introduction}

Lung cancer is the leading cause of cancer-related death in the world (1). Lung cancer was the leading indication for respiratory surgery (42.2\%) in 1998 in Japan (2). More than 15000 patients underwent surgical operation at Japanese institutions in 1998 (2). Despite the advances made in surgery,

Correspondence to: Dr Hidefumi Sasaki, Department of Surgery II, Nagoya City University Medical School, Kawasumi 1, Mizuho-cho, Mizuho-ku, Nagoya 467-8601, Japan

E-mail: hisasaki@med.nagoya-cu.ac.jp

Key words: epidermal growth factor receptor variant III, lung cancer, mutations, epidermal growth factor receptor, genotype chemotherapy, and radiotherapy, the overall 5-year survival rate still remains at $15 \%$. Other therapeutic targets and agents are needed for the management of non-small cell lung cancer (NSCLC).

Overexpression of the epidermal growth factor receptor $(E G F R)$ in multiple human tumors has been extensively documented and alterations within the $E G F R$ gene may be as important as overexpression for oncogenic effect $(3,4)$. EGFR is abundantly expressed in NSCLC $(5,6)$. EGFR tyrosine kinase inhibitor, gefitinib, was approved in Japan for the treatment of NSCLC from 2002. We have found that EGFR mutation status at kinase domain in Japanese NSCLC patients was correlated with the clinicopathological features related to good response to gefitinib (7-10). EGFR mutations in lung cancer have been correlated with clinical response to gefitinib therapy in vivo and in vitro $(7,11,12)$. More recently, another EGFR inhibitor cetuximab was approved for treatment of colon cancer. It has been reported that $E G F R$ gene amplification is correlated with clinical response to cetuximab therapy (13). Clinical trails for lung cancer using cetuximab are underway (14).

Most common of the rearrangements in human gliomas were genomic alterations leading to deletion of exon 2-7 in the EGFR mRNA (EGFRvIII), which causes an in-frame truncation of $801 \mathrm{bp}$ in the extracellular domain of the molecule expressed in 24-67\% of cases (15-18). This EGFRvIII mutation is highly correlated with $E G F R$ amplification $(19,20)$. Previous work has shown that $16 \%$ of NSCLC expressed EGFRvIII (21), and another study showed that $39 \%$ of NSCLC had EGFRvIII mutation (22). However, these results were confirmed by immunohistochemical analysis.

The standard for experimental detection of mutations is direct sequencing of DNA samples from the tissues. However, for known mutations, real-time polymerase chain detection followed by melting curve analysis, using hybridization probes, is highly sensitive, rapid and an efficient alternative approach to mutation detection $(8,23,24)$. To determine the EGFR mutation status in Japanese lung carcinoma for screening and diagnostic purpose, we wanted to develop a faster and easier method to detect EGFRvIII mutations. In this study, we investigated EGFRvIII mutation status by the real-time RTPCR assay using LightCycler (24) mutation specific sensor and anchor probes. Among the screening sequencing for total $E G F R$ gene, two EGFRvIII mutation patients were found (25). These samples were used as a positive control for further 
study. The findings were compared to the clinicopathologic features of lung cancer.

\section{Patients and methods}

Patients. The study group included 252 lung cancer patients who had undergone surgery at the Department of Surgery II, Nagoya City University Medical School Hospital between 1997 and 2003. All tumor samples were immediately frozen and stored at $-80^{\circ} \mathrm{C}$ until assayed. These samples were sequenced for EGFR kinase domain by ABI PRISM 3100 analyzer (Applied Biosystems Japan Ltd., Tokyo, Japan) $(7,9)$ and analyzed by ABI PRISM Seq Scape version 2.1.1.

The clinical and pathological characteristics of the 252 lung cancer patients were: 132 cases at stage I, 38 at stage II, and 82 at stage III-IV. The mean age was 65.3 years (range, 42-88). Among the 252 lung cancer patients, 139 (55.1\%) were diagnosed as adenocarcinoma, 87 (34.5\%) were squamous cell carcinoma, $12(4.8 \%)$ were adenosquamous cell carcinoma, and $6(2.4 \%)$ were large cell carcinoma. Written informed consent was obtained from the patients, and the study was approved by the institutional ethics committee of the Nagoya City University Medical School.

PCR assays for EGFRvIII. Total RNA was extracted from lung cancer tissues and adjacent non-malignant lung tissues using Isogen kit (Nippon Gene, Tokyo, Japan) according to the manufacturer's instructions. RNA concentration was determined by a spectrophotometer and adjusted to a concentration of $200 \mathrm{ng} / \mathrm{ml}$. RNA ( $1 \mu \mathrm{g})$ was reverse transcribed by Superscript II enzyme (Gibco BRL, Gaithersburg, MD) with $0.5 \mu \mathrm{g}$ oligo(dT) $)_{12-16}$ (Amersham Pharmacia Biotech Inc. Piscataway, NJ). Initially, several cDNA samples were also sequenced and EGFRvIII mutations found (25). The sets of cDNA were used as a positive and negative control for genotyping. DNA concentration was determined by spectrophotometer and adjusted to a concentration of $50 \mathrm{ng} / \mathrm{ml}$. We then used $1 \mu \mathrm{l}$ of each DNA for LightCycler analyses. To ensure the fidelity of cDNA transcription, all samples were subjected to PCR amplification with oligonucleotide primers specific for the constitutively expressed gene glyceraldehyde-3phosphate dehydrogenase. The genotyping PCR reactions were performed using LightCycler DNA Master hybridization probe kit (Roche Molecular Biochemicals, Mannheim, Germany) in a $20-\mu 1$ reaction volume. The primer sequences for EGFR $V I I I$ gene were: forward primer, 5-CAGTATTGATCGGGAG AG-3 and the reverse primer, 5-CATCTCATAGCTGT CGGC-3 (197 bp). For EGFRvIII genotyping, sensor (TGCGCTCTGCCCGGCGAGTGGG-fluorescein) and anchor (LC Red 640 TCTGGAGGAAAAGAAAGGTA ATTATGTGGTG-phosphate) probes were used.

EGFR DNA copy number. The EGFR gene copy number was analyzed by quantitative real-time PCR, performed on a PRISM 750 sequence detector (Applied Biosystems) by using a QunatiTect SYBR Green kit (Qiagen, Inc., Valencia, CA) (9). We quantified each tumor DNA by comparing the target locus to the reference Line-1, repetitive element for which copy numbers per haploid genome are similar among all of the human normal and neoplastic cells. Quantification is
Table I. Clinicopathological data of 252 lung cancer patients.

\begin{tabular}{|c|c|c|c|}
\hline \multirow[b]{2}{*}{ Factors } & \multicolumn{3}{|c|}{ EGFR kinase domain mutations } \\
\hline & $\begin{array}{l}\text { Mutation } \\
\text { patients }\end{array}$ & $\begin{array}{l}\text { Wild-type } \\
\text { patients }\end{array}$ & p-value \\
\hline \multicolumn{4}{|l|}{ Mean age (years) } \\
\hline $65.5 \pm 9.3$ & 60 & 192 & \\
\hline \multicolumn{4}{|l|}{ Age } \\
\hline$\leq 60$ & $21(28.8 \%)$ & $52(71.2 \%)$ & 0.3092 \\
\hline$>60$ & $39(21.8 \%)$ & $140(78.2 \%)$ & \\
\hline \multicolumn{4}{|l|}{ Gender } \\
\hline Male & $21(11.2 \%)$ & $167(88.8 \%)$ & $<0.0001$ \\
\hline Female & $39(60.9 \%)$ & $25(39.1 \%)$ & \\
\hline \multicolumn{4}{|c|}{ Pathological subtypes } \\
\hline Adeno & $56(40.3 \%)$ & $83(59.7 \%)$ & $<0.0001$ \\
\hline Non-adeno & $4(3.5 \%)$ & $109(96.5 \%)$ & \\
\hline \multicolumn{4}{|l|}{ Differentiation } \\
\hline Well & $43(44.8 \%)$ & $53(55.2 \%)$ & $<0.0001$ \\
\hline $\begin{array}{l}\text { Moderately or } \\
\text { Poorly }\end{array}$ & $14(11.3 \%)$ & $110(88.7 \%)$ & \\
\hline \multicolumn{4}{|c|}{ Lymph node metastasis } \\
\hline No & $46(27.1 \%)$ & $124(82.9 \%)$ & 0.1128 \\
\hline $\mathrm{N}+$ & $14(17.1 \%)$ & $68(88.7 \%)$ & \\
\hline \multicolumn{4}{|l|}{ Smoking status } \\
\hline Smoker & $20(11.0 \%)$ & $162(89.0 \%)$ & $<0.0001$ \\
\hline Non-smoker & $40(57.1 \%)$ & $30(42.9 \%)$ & \\
\hline \multicolumn{4}{|l|}{ Pathological stages } \\
\hline I & $40(30.3 \%)$ & $92(69.7 \%)$ & 0.0168 \\
\hline II-IV & $20(16.7 \%)$ & $100(83.3 \%)$ & \\
\hline
\end{tabular}

$\mathrm{N}+$, lymph node metastasis positive; Adeno, adenocarcinoma.

based on standard curve from a serial dilution of human normal lung genomic DNA. The relative EGFR copy number level was normalized to normal human genomic DNA as calibrator. Copy number change of EGFR gene relative to the Line- 1 and the calibrator were determined by using the formula $\left(\mathrm{T}_{\text {EGFR }} / \mathrm{T}_{\text {Line-1 }}\right) /\left(\mathrm{C}_{\text {EGFR }} / \mathrm{C}_{\text {Line-1 }}\right)$, where $\mathrm{T} E G F R$ and $\mathrm{T}_{\text {Line-1 }}$ are quantity from tumor DNA by using target and Line-1. PCRs for each primer set were performed in at least triplicate, and means were reported. Conditions for quantitative PCR reaction were: one cycle of $50^{\circ} \mathrm{C}$ for $2 \mathrm{~min}$, one cycle of $95^{\circ} \mathrm{C}$ for $15 \mathrm{~min}, 40 \mathrm{cycles}$ of $95^{\circ} \mathrm{C}$ for $15 \mathrm{sec}, 56^{\circ} \mathrm{C}$ for $30 \mathrm{sec}$, and $72^{\circ} \mathrm{C}$ for $34 \mathrm{sec}$. At the end of the PCR reaction, samples were subjected to a melting analysis to confirm specificity of the amplicon. Primer sequences for $E G F R$ gene used are: forward: CCACCAAATTAGCCTGGACA and reverse: CGCGACC TTAGGTATTCTG.

Statistical analysis. Statistical analyses were done using the Mann-Whitney U test for unpaired samples and Wilcoxon's 

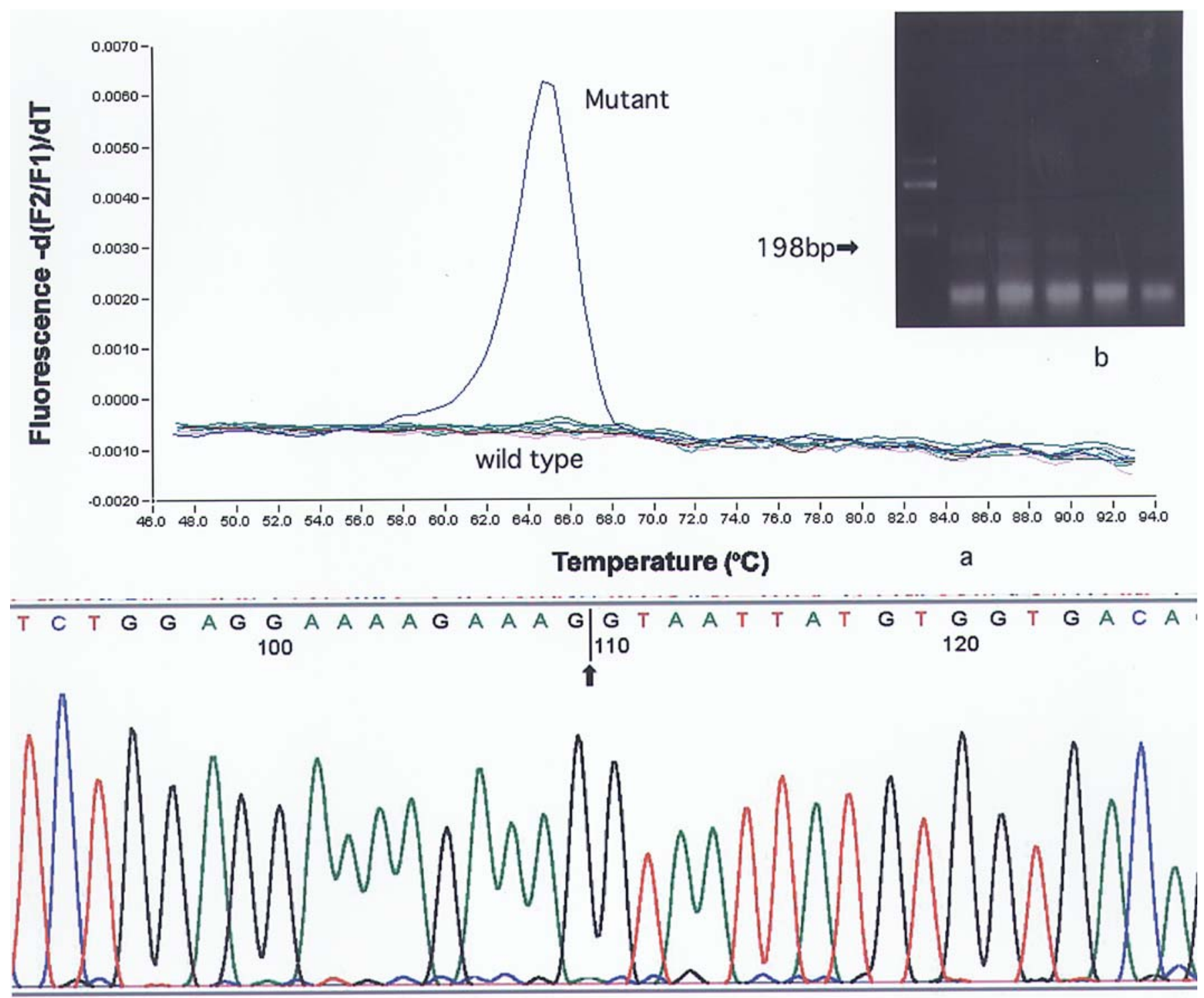

C

Figure 1. The sequencing of analyzed data using RT-PCR (direct sequencing) method. (a) Detection of an EGFRvIII mutation in cDNA extracted from lung cancer tissues. The negative derivative of the fluorescence $(-\mathrm{dF} / \mathrm{dT})$ versus temperature graph shows peaks with different Tm. The EGFR $I I I$ mutation through exon 2-7 PCR product showed a single peak at $63^{\circ} \mathrm{C}$, whereas the wild-type showed no peak. (b) The products were loaded on $1 \%$ agarose gel. The products were 198 bp. (c) The sequencing data of PCR products lacked exon 2-7 in the EGFR mRNA (EGFRvIII), which causes an in-frame truncation of 801 bp.

signed rank-test for paired samples. Linear relationships between variables were determined by means of simple linear regression. Correlation coefficients were determined by rank correlation using Spearman's test and $\chi^{2}$ test. The analyses were done using the Stat-View software package (Abacus Concepts Inc. Berkeley, CA), and was considered significant at p-value $<0.05$.

\section{Results}

Sequence results for EGFR gene at kinase domain in lung cancer tissues. The EGFR mutation status in kinase domain was reported (7-9). From the 252 lung cancer patients, 60 had an activating mutation; 21 were male $(35.0 \%)$ and 39 were female. Forty were non-smokers $(66.7 \%)$ and 20 were smokers. Fifty-five patients had adenocarcinoma (91.7\%), 3 had squamous cell carcinoma and 2 had adenosquamous cell carcinoma. Thus, EGFR mutation status at kinase domain was significantly correlated with gender, smoking status and the pathological subtypes (adenocarcinoma vs. others) of lung cancer $(\mathrm{p}<0.0001)$ (Table I).

Genotyping of EGFRvIII in lung cancer tissues. For genotyping, the anchor probe was matched for EGFRvIII mutation. As shown in Fig. 1, EGFRvIII mutation through exon 2-7 PCR products showed a single peak at $63^{\circ} \mathrm{C}$, whereas the wild-type showed no peak. From the 252 lung cancer patients, 8 had an EGFRvIII mutation (Table II). Adjacent matchedlung tissues (7/8) were available and showed no peak from PCR assays, suggested that these EGFRvIII mutations were somatic. All were male and smokers. Brinkman index was significantly higher in EGFRvIII mutant (1627.5 \pm 824.1$)$ than in non-EGFRvIII patients $(736.3 \pm 680.4)(\mathrm{p}=0.0001)$. Seven patients had squamous cell carcinoma and 1 had an adeno- 
Table II. Clinicopathological data of 8 lung cancer patients with EGFRvIII.

\begin{tabular}{lccclc}
\hline Gender & Age & Smoking status & Histology & Differentiation & EGFR kinase domain mutation \\
\hline M & 61 & Smoker & SCC & Poor & WT \\
M & 75 & Smoker & SCC & Moderately & WT \\
M & 63 & Smoker & SCC & Moderately & WT \\
M & 69 & Smoker & SCC & Moderately & WT \\
M & 75 & Smoker & SCC & Well & WT \\
M & 66 & Smoker & Adeno & Poor & WT \\
M & 67 & Smoker & SCC & Moderately & WT \\
M & 58 & Smoker & SCC & Well & WT \\
\hline
\end{tabular}

M, male; F, female; SCC, squamous cell carcinoma; WT, wild-type.

carcinoma. Adenocarcinoma patients $0.7 \%$ (1/139) and squamous cell carcinoma patients $8.0 \%$ (7/87) had EGFRvIII mutations. Squamous cell carcinoma patients had significantly higher incidence of EGFRvIII mutations than adenocarcinoma patients $(\mathrm{p}=0.0114)$. EGFRvIII mutant patients did not have EGFR mutations at kinase domain. Thus, EGFRvIII mutation and EGFR mutation at kinase domain were exclusive.

Of the 252 NSCLC patients, 14 were treated with gefitinib after relapse of lung cancers. Nine EGFR kinase domain mutations were detected from these 14 lung cancer specimens. In 7 patients gefitinib therapy was effective; 6/7 gefitinib responder had EGFR kinase domain mutations. On the contrary, no EGFRvIII mutation was found in the 7 gefitinib responder patients.

Analysis of EGFR DNA copy number. The EGFR gene copy number of 131 samples from lung cancer patients was analyzed by quantitative real-time PCR. Of $131(8.4 \%)$ cases, 11 were found to have EGFR DNA amplifications (copy number $>3$ ). Of $8(37.5 \%)$ EGFRvIII mutant patients, 3 had increased copy number. The FISH analyses for two EGFRvIII mutant patients with $E G F R$ increased copy number, were published as supporting information (25).

$E G F R$ gene copy number was significantly higher in EGFRvIII samples $(4.711 \pm 4.968)$ than in non-EGFRvIII samples $(2.284 \pm 1.224)(\mathrm{p}=0.0001)$.

\section{Discussion}

We obtained results that the incidence of EGFRvIII mutation was higher in patients with squamous cell than adenocarcinomas. Somatic EGFRvIII mutation existed exclusively with $E G F R$ kinase domain mutations. Recent studies have shown that EGFR gene mutations at kinase domain are common in lung cancers from 'never smokers' and females with adenocarcinoma (7-10). Our analysis suggested that the population of somatic EGFRvIII mutations and the EGFR mutations at kinase domain in lung cancers was different. Increased copy number of EGFR gene was seen in EGFRvIII samples.

The development of immunotherapy strategies for NSCLC will be facilitated by the identification of tumor-specific targets. Although the EGFR is overexpressed in many cases of NSCLC, its wide distribution in normal tissue, such as liver and skin may limit its suitability as an immunotherapeutic agent. The anti-EGFR monoclonal antibody, cetuximab, has good clinical activity in $\sim 10 \%$ of patients with metastatic colorectal cancer $(13,26)$. The cetuximab treatment for NSCLC appears promising from preclinical data $(14,27)$. However, the mutation status of the EGFR catalytic domain and its immediate downstream effectors PIK3CA, $K R A S$, and $B R A F$ did not correlate with disease response to cetuximab (13). Most colon cancer patients with objective response had an increased EGFR copy number (13). Previous work has shown that the positive staining with the EGFRvIII antibody was highly correlated with EGFR amplification (18). Thus, it would be of interest to determine whether sensitivity to EGFR antibody therapy emerges through EGFRvIII mutation. Mutations within the EGFR that are unique to malignancies may provide specific targets for immunotherapeutic intervention. The importance of EGFRvIII as a new anti-cancer therapeutic target was recently highlighted (28-30). Monoclonal antibody 806 inhibited the tumor growth expressing EGFRvIII of amplified EGFR but not wild-type $E G F R$ (30).

Of the naturally occurring variant forms, EGFRvIII is the most common and is present in 50-60\% of high grade gliomas, $70 \%$ of breast carcinomas, and $70 \%$ of ovarian neoplasms, but not in normal tissues (31). Structurally, the EGFRvIII gene is missing 801 coding bases, spanning exons 2-7 of the wild-type gene (15-22,31). Since our results showed fewer EGFRvIII mutation incidences than previous studies $(21,22)$, some other EGFRvIII mutation phenotypes might exist.

Cappuzzo et al reported that high EGFR copy number identified by FISH, but not EGFR mutation at kinase domain, might be an effective molecular predictor for efficacy of gefitinib in NSCLC (32). Tsao et al reported that high copy number of EGFR, but not EGFR mutation at kinase domain, correlated with longer survival in erlotinib-treated NSCLC patients (33), although, in the Japanese population, these data are controversial (34). A recent study showed that EGFRvIII mutant tumors intermediate responded to gefitinib and erlotinib. EGFRvIII mutant cell lines or tumor strongly responded to HKI-272, another tyrosine kinase inhibitor. Thus, detection of EGFR mutations should be of clinical 
importance in predicting the sensitivity or resistance to molecular-target therapy for lung cancer, especially in squamous cell lung carcinomas.

\section{Acknowledgements}

We would like to thank Mrs. Yuri Yamamoto for her excellent technical assistances. Financial support: AstraZeneca Research Grant 2004 and Grants-in-Aid for Science Research (Nos. 18659407, 18390381, 18790998) from the Ministry of Education, Culture, Sports, Science and Technology (MEXT), Japan.

\section{References}

1. Bunn PA Jr and Kato H: Current perspectives in the treatment of non-small cell lung cancer. Semin Oncol 28: 1-2, 2001.

2. Yasuda K, Ayabe H, Ide H and Uchida Y: On behalf of the Japanese Association for Thoracic Surgery: thoracic and cardiovascular surgery in Japan during 1998. Annual report by the Japanese association for thoracic surgery. Jpn J Cardiothorac Surg 48: 401-415, 1998.

3. Di Fiore PP, Pierce JH, Fleming TP, et al: Overexpression of the human EGF receptor confers an EGF-dependent transformed phenotype to NIH3T3 cells. Cell 51: 1063-1070, 1987.

4. Velu TJ, Beguinot L, Vass WC, et al: Epidermal-growth-factordependent transformation by a human EGF receptor protooncogene. Science 238: 1408-1410, 1987.

5. Rusch V, Baselga J, Cordon-Cardo C, et al: Differential expression of the epidermal growth factor receptor and its ligands in primary non-small cell lung cancers and adjacent benign lung. Cancer Res 53: 2379-2385, 1993.

6. Sasaki H, Yukiue H, Mizuno K, et al: Elevated serum epidermal growth factor receptor level is correlated with lymph node metastasis in lung cancer. Int J Clin Oncol 8: 79-82, 2003.

7. Paez JG, Janne PA, Lee JC, et al: EGFR mutations in lung cancer: correlation with clinical response to gefitinib therapy. Science 304: 1497-1500, 2004.

8. Sasaki H, Endo K, Konishi A, et al: EGFR mutation status in Japanese lung cancer patients: genotyping analysis using LightCycler. Clin Cancer Res 11: 2924-2929, 2005.

9. Endo K, Konishi A, Sasaki H, et al: Epidermal growth factor receptor gene mutation in non-small cell lung cancer using highly sensitive and fast TaqMan PCR assay. Lung Cancer 50: 375-384, 2005.

10. Sasaki H, Shimizu S, Endo K, et al: EGFR and erbB2 mutation status in Japanese lung cancer patients. Int J Cancer 118: 180-184, 2006.

11. Lynch TJ, Bell DW, Sordella R, et al: Activating mutations in the epidermal growth factor receptor underlying responsiveness of non-small cell lung cancer to gefitinib. N Engl J Med 350: 2129-2139, 2004

12. Pao W, Miller V, Zakowski M, et al: EGF receptor gene mutations are common in lung cancers from 'never smokers' and are associated with sensitivity of tumors to gefitinib and elrotinib. Proc Natl Acad Sci USA 101: 13306-13311, 2004.

13. Moroni M, Veronese S, Benvenuti S, et al: Gene copy number for epidermal growth factor receptor and clinical response to anti-EGFR treatment in colorectal cancer: a cohort study. Lancet Oncol 6: 279-286, 2005.

14. Baselga J, Pfister D, Cooper MR, et al: Phase I study of antiepidermal growth factor receptor chimeric antibody C225 alone and in combination with cisplatin. J Clin Oncol 18: 904-914, 2000.

15. Wong AJ, Ruppert JM, Bigner SH, et al: Structural alterations of the epidermal growth factor receptor gene in human gliomas. Proc Natl Acad Sci USA 89: 2956-2959, 1992.
16. Sugawa N, Ekstrabd AJ, James CD and Collins VP: Identical splicing of aberrant epidermal growth factor receptor transcripts from amplified rearranged genes in human glioblastomas. Proc Natl Acad Sci USA 87: 8602-8606, 1990.

17. Nishikawa R, Ji XD, Harmon RC, et al: A mutant epidermal growth factor receptor common in human glioma confers enhanced tumorigenicity. Proc Natl Acad Sci USA 91: 7727-7731, 1994.

18. Ekstrand AJ, Longo N, Hamid ML, et al: Functional characterization of an EGF receptor with a truncated extracellular domain expressed in gliomas with EGFR gene amplification. Oncogene 9: 2313-2320, 1994

19. Wikstand CJ, McLendo RE, Friedman AH and Binger DD: Cell surface localization and density of the tumor-associated variant of the epidermal growth factor receptor, EGFRvIII. Cancer Res 57: 4130-4140, 1997.

20. Aldape K, Ballman K, Furth A, et al: Immunohistochemical detection of EGFRvIII in high malignancy grade astrocytomas and evaluation of prognostic significance. J Neuropathol Exp Neurol 63: 700-707, 2004.

21. Garcia de Palazzo IE, Adams GP, Sundareshan P, et al: Expression of mutated epidermal growth factor receptor by nonsmall cell lung carcinomas. Cancer Res 53: 3217-3220, 1993.

22. Okamoto I, Kenyon LC, Emlet DR, et al: Expression of constitutively activated EGFRvIII in non-small cell lung cancer. Cancer Sci 94: 50-56, 2003.

23. Wittwer CT, Herrmann MG, Moss AA and Rasmussen RP: Continuous fluorescence monitoring of rapid cycle DNA amplification. Biotechniques 22: 130-138, 1997.

24. Wittwer T, Ririe M, Andrew V, David A, Gungry A and Balis J: The LightCycler: a microvolume multisample fluorimeter with rapid temperature control. Biotechniques 22: 176-181, 1997.

25. Ji H, Zhao X, Yuza Y, et al: Epidermal growth factor receptor variant III mutations in lung tumorigenesis and sensitivity to tyrosine kinase inhibitor. Proc Natl Acad Sci USA 103: 7817-7822, 2006.

26. Cunningham D, Humblet Y, Siena S, et al: Cetuximab monotherapy and cetuximab plus irinotecan in irinotecan-refractory metastatic colorectal cancer. N Engl J Med 351: 337-345, 2004.

27. Raben D, Helfrich B, Cha DC, et al: The effects of cetuximab alone and in combination with radiation and/or chemotherapy in lung cancer. Clin Cancer Res 11: 795-805, 2005.

28. Pedersen MW, Meltor M, Damstrup L and Poulse HS: The type III epidermal growth factor receptor mutation. Biological significance and potential target for anti-cancer therapy. Ann Oncol 12: 745-760, 2001

29. Moscatello DK, Ramirez G and Wong AL: A naturally occurring mutant human epidermal growth factor receptor as a target for peptide vaccine immunotherapy of tumors. Cancer Res 57: 1419-1424, 1997.

30. Luwor RB, Johns TG, Murone C, et al: Monoclonal antibody 806 inhibit the growth of tumor xenografts expressing either the de2-7 or amplified epidermal growth factor receptor (EGFR) but not wild-type EGFR. Cancer Res 61: 5355-5361, 2001.

31. Chu CT, Everiss KD, Wikstrand CJ, Batra SK, Kung HJ and Bigner DD: Receptor dimerization is not a factor in the signaling activity of a transforming variant epidermal growth factor receptor (EGFRvIII). Biochem J 324: 855-861, 1997.

32. Cappuzzo F, Hirsc FR, Rossi E, et al: Epidermal growth factor receptor gene and protein and gefitinib sensitivity in non-small cell lung cancer. J Natl Cancer Inst 97: 643-655, 2005.

33. Tsao MS, Sakurada A, Cutz JC, et al: Erlotinib in lung cancermolecular and clinical predictor of outcome. N Engl J Med 353: 133-144, 2005.

34. Takano T, Ohe Y, Sakamoto H, et al: Epidermal growth factor receptor gene mutations and increase copy numbers predict gefitinib sensitivity in patients with recurrent non-small cell lung cancer. J Clin Oncol 23: 6829-6837, 2005. 